\title{
Neuroprotective Effects of Lacosamide in Experimental Traumatic Spinal Cord Injury in Rats
}

\author{
Serdar DEMIROZ ${ }^{1}$, Koray UR², Aykut ULUCAN${ }^{3}$, Aydin Sukru BENGU ${ }^{4}$, Feyza DEMIRALIN UR ${ }^{5}$, \\ Ozlem Oz GERGIN ${ }^{6}$, Sevki ERDEM ${ }^{7}$ \\ ${ }^{1}$ Bingol State Hospital, Department of Orthopaedics and Traumatology, Bingol, Turkey \\ ${ }^{2}$ Bingol State Hospital, Department of Neurosurgery, Bingol, Turkey \\ ${ }^{3}$ Bingol University Vocational School of Health Services, Department of Medical Services and Techniques, Pathology Laboratory Programme, \\ Bingol, Turkey \\ ${ }^{4}$ Bingol University Vocational School of Health Services, Department of Medical Services and Techniques, Medical Laboratory Programme, \\ Bingol, Turkey \\ ${ }^{5}$ Bingol State Hospital, Department of Neurology, Bingol, Turkey \\ ${ }^{6}$ Kayseri Education and Research Hospital, Department of Anesthesiology and Reanimation, Kayseri, Turkey \\ ${ }^{7}$ Medicana Kadikoy Hospital, Department of Orthopaedics and Traumatology, Istanbul, Turkey
}

Corresponding author: Serdar DEMIROZ serdardemiroz@hotmail.com

\section{ABSTRACT}

AIM: To evaluate the effects of lacosamide on traumatic spinal cord injury (SCI) in rats.

MATERIAL and METHODS: A total of 28 male Wistar albino rats, each weighing 300-350 g, were included. They were randomly assigned to four groups. In Group 1, only a laminectomy was performed; in Group 2, SCl was performed after laminectomy; in Group 3, SCl was performed after laminectomy followed by lacosamide administration, and in Group 4, SCl was performed after laminectomy followed by physiological saline administration. After 48 hours, all animals were sacrificed, blood samples were drawn, and their spinal cords were removed. The serum levels of catalase, glutathione peroxidase (GPx), superoxide dismutase (SOD) and malondialdehyde (MDA) were measured, and the spinal cord specimens were examined for neuronal degeneration (PND).

RESULTS: The MDA level was the lowest and the antioxidant enzyme levels were the highest in Group 3 . There were statistically significant differences between Group 3 and the others in their PND score, serum MDA, SOD, GPX and catalase levels ( $<<0.05$ ).

CONCLUSION: Lacosamide has a neuroprotective effect in $\mathrm{SCI}$ in rats that is related to its ability to decrease the production of reactive oxygen species by increasing antioxidant enzyme expression, inhibit lipid peroxidation and attenuate glial cell activation.

KEYWORDS: Lacosamide, Spinal cord injury, Neuroprotective agents, Oxidative stress, Rat

\section{INTRODUCTION}

$\mathrm{T}$ Traumatic spinal cord injury (SCl) is a catastrophic event that results in disparate outcomes ranging from complete recovery to paraplegia, tetraplegia or death (21). In humans, $\mathrm{SCl}$ is most commonly caused by a combination of acute impact and persistent compression and shows two consecutive stages (5). First, the vertebral fracture fragments lead to contusion and compression of the spinal cord, which is called primary injury. There after, the secondary injury follows, which is characterised by ischemic dysfunction, inflammation, occurrence of oxygen-free radicals, lipid peroxidation and apoptosis $(6,10,23,29)$. This secondary injury has been the therapeutic target in most studies designed to determine whether pharmacologic agents have neuroprotective effects after SCI $(3,19,26)$.
Serdar DEMIROZ (1) : 0000-0002-2403-3750

Koray UR

Aykut ULUCAN
(1) : 0000-0002-2755-5992

(1) : 0000-0001-8844-8237
Aydin Sukru BENGU (1): 0000-0002-7635-4855

Feyza DEMIRALIN UR (D) : 0000-0001-7540-0971
Ozlem OZ GERGIN (1) : 0000-0002-1720-0194

Sevki ERDEM
(D) : $0000-0002-3977-3380$ 
Several studies have investigated pharmacologic agents that were presumed to have neuroprotective effects after SCl, but only methylprednisolone has shown beneficial effects in large clinical studies $(13-15,30,31,33)$. Although it has beneficial effects on parenchymal damage, there is no significant improvement of functional recovery (25).

Lacosamide is a new pharmaceutical candidate for neuroprotection after traumatic $\mathrm{SCl}$. In addition to its antiepileptic function, lacosamide has been shown to protect nervous system tissue. It improves functional performance in rodent models after traumatic brain injury $(12,22)$, and pretreatment with lacosamide has shown a neuroprotective effect after transient global cerebral ischaemia (1). This neuroprotective capacity has been linked to lacosamide's anti-inflammatory properties and its ability to inhibit glial cell proliferation and lipid peroxidation, which are pathogenetic in the secondary injury phase of traumatic SCI (27). Therefore, we hypothesised that lacosamide may provide neuroprotective effects after traumatic SCl.

The purpose of the present study was to evaluate the effects of lacosamide on the injured spinal cord of rats and the serum levels of the antioxidant enzymes catalase, glutathione peroxidase (GPx) and superoxide dismutase (SOD), as well as the lipid peroxidation end-product malondialdehyde (MDA).

\section{MATERIAL and METHODS}

The study protocol was approved by the local ethics committee (29.12.2016; no: 07/04). A total of 28 male Wistar albino rats, each weighing $300-350 \mathrm{~g}$, were included in this study. They were randomly split into four groups that received different treatments as follows: in Group 1, only a laminectomy was performed; in Group 2, SCl was imitated after laminectomy; in Group 3, lacosamide was administered after the $\mathrm{SCl}$ and in Group 4, physiological saline solution was administered instead.

The exact procedures were performed as follows: all rats were kept under environmentally controlled conditions. They were anaesthetised with an intraperitoneal injection of $10 \mathrm{mg} /$ $\mathrm{kg}$ of xylazine (Alfazyne; Egevet, Izmir, Turkey) and $50 \mathrm{mg} / \mathrm{kg}$ of ketamine (Ketalar; Parke-Davis, Eczacibasi, Turkey). The rats were placed in the prone position, and their backs were shaved and cleaned with 10\% polyvidone iodine (Batticon; Adeka, Samsun, Turkey). A midline skin incision was made from T7 to T12, the paravertebral muscles were dissected, and a total laminectomy was performed under the microscope at the level T10-11. After laminectomy, the surgical wound was closed in Group 1. After the same laminectomy, a vascular clip (Scanlan ${ }^{\circledR}$ Vascu-Statt ${ }^{\circledR}$; Scanlan, SaintPaul, MN, USA) with a $40 \mathrm{~g}$ closing force was applied to the spinal cord at level T10-11 in Group 2, and then the wound was closed. The rats in Group 3 received the same intervention before lacosamide was administered intraperitoneally at a dose of 30 $\mathrm{mg} / \mathrm{kg}$ at 8-hour intervals. The first dose of drug administered immediately after closing the skin after spinal trauma and the last dose administered 8 hours before the sacrification. Rats recieved a total of 7 doses of medication. In Group 4, physiological saline was administered at the same doses and intervals as the third group.

In all groups, we compressed the spinal cord for one minute, which was designed to be sufficient to cause mild to severe damage (Figure 1) (18).

Forty-eight hours after the injury, all animals were sacrificed by decapitation under deep anaesthesia and an autopsy performed according to the Virchow technique. A $5.0 \mathrm{~mL}$ blood sample was drawn for biochemical analysis, and the spinal cords were removed for histopathological examination. Blood samples were centrifuged at 1,500 rpm for 15 minutes to separate the serum, and serum samples were stored at $-40^{\circ} \mathrm{C}$ before analysing the GPx, SOD, catalase and MDA levels, using a commercial enzyme-linked immunosorbent assay kit (SunRed; Sunred Biological Technology Co., Ltd., Shanghai, China; catalogue numbers SOD:201-11-0169; GPx:201-115104; catalase:201-11-5106; MDA:201-11-0157).

Spinal cord tissue samples were fixed in $10 \%$ buffered formaldehyde solution, processed using a routine dehydration protocol in ascending grades of ethanol, cleared in xylene and embedded in paraffin. Paraffin-embedded tissue samples were sectioned into $5-\mu \mathrm{m}$ thick slices with a rotary microtome (RM2125; Leica, Wetzlar, Germany). The slides were stained with haematoxylin and eosin for histopathological examination. Finally, the slides were examined and photographed using a light microscope with an imaging system (DM2500/DFC295; Leica, Wetzlar, Germany). The histopathological findings including the extent of the inflammatory reaction were examined using light microscopy. The inflammatory reaction was assessed using an immunohistochemistry scoring system (modified Allred system) and revealed the presence of neuronal degeneration (PND). The PND score was considered as the ratio of the amount of glial cell proliferation to the normal tissue in the region of tissue damage and was classified into the following grades; negative $=0 ;<1 \%=1 ; 1 \%-9 \%=2 ; 10 \%-$ $32 \%=3 ; 33 \%-65 \%=4$ and $>65 \%=5(9)$.

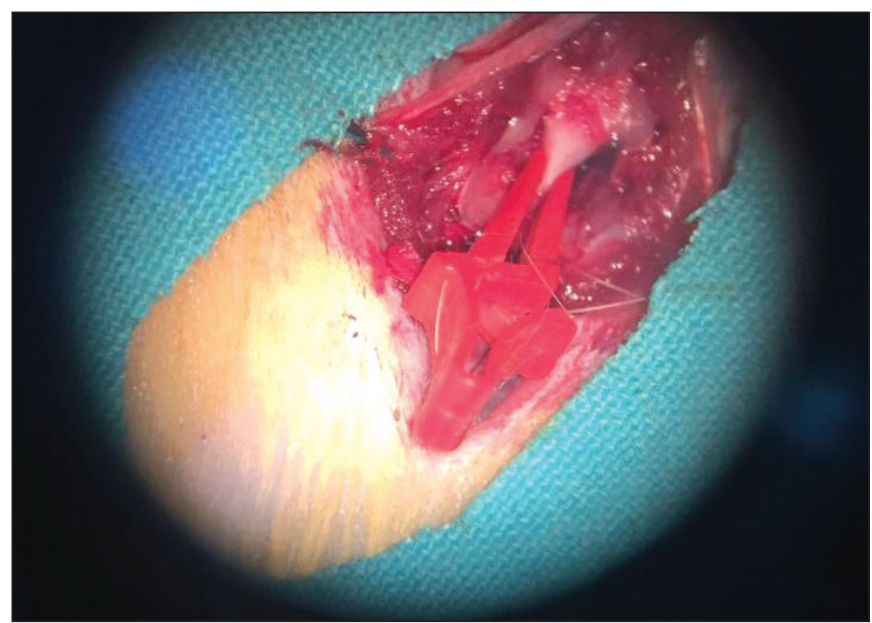

Figure 1: Illustration of the spinal cord injury induced in Wistar rats $(n=28)$ : compression of the spinal cord with a clamp exerting a $40 \mathrm{~g}$ closing force. 
All data were analysed using SPSS Statistics for Windows, version 20.0 (IBM Corp., Armonk, NY, USA). The MannWhitney $U$ test was used to compare the descriptive statistical measurements (mean, standard deviation, minimum and maximum) and the parameters that did not show a normal distribution in the quantitative data comparison. One-way analysis of variance was applied to assess the differences among the groups. Statistical significance was determined as $\mathrm{p}<0.05$.

\section{- RESULTS}

The spinal cord tissue showed a normal histological appearance in Group 1 (Figure 2A). In Group 2, severe perineural vacuolations of the motor nuclei of the neurons, neuronal shrinkage, loss of neurons, degeneration and
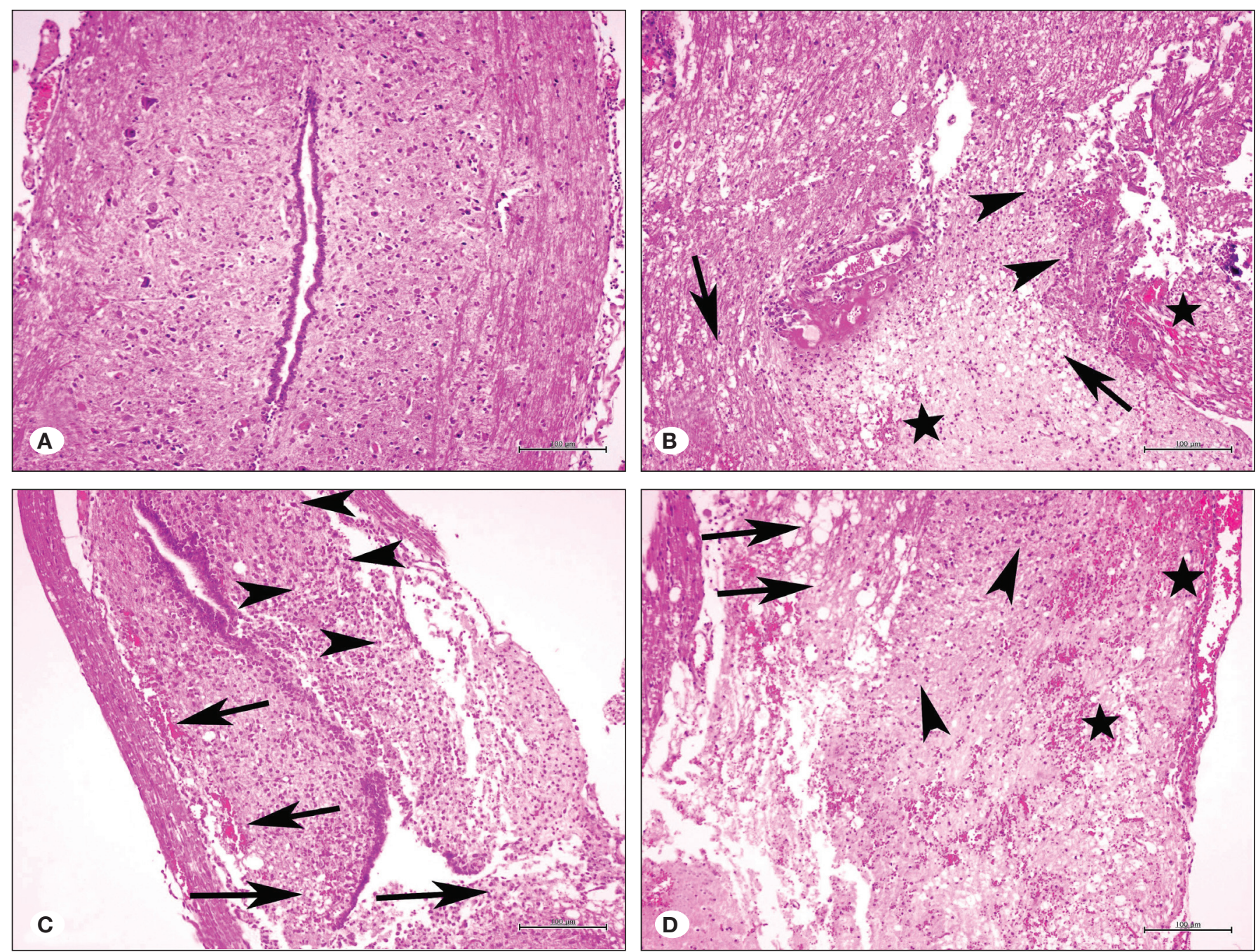

Figure 2: Histopathology of the spinal cord tissues (light microscopy, $\times 100$ magnification; haematoxylin and eosin staining). A) Group 1: normal histological structure of the medulla spinalis. B) Group 2: severe neuronal loss and proliferation of glial cells (arrow heads), diffuse spongious appearance (arrows) of white matter and diffuse haemorrhage (stars). C) Group 3: degeneration of neurons (left arrow heads), mild congestion (left arrows), proliferation of glial cells (right arrow heads) and spongious appearance (right arrows) of white matter. D) Group 4: severe neuronal loss and proliferation of glial cells (arrow heads), diffuse spongious appearance (arrows) of white matter and diffuse haemorrhage (stars). 
Table I: Biochemical and Pathological Results Relevant to the Groups

\begin{tabular}{lccccc}
\hline & Group 1 (sham) & Group 2 (SCI) & Group 3 (SCI + L) & Group 4 (SCI + PS) & p $^{*}$ \\
\hline MDA $(\mathrm{ng} / \mathrm{mL})$ & $1.18 \pm 0.154$ & $1.35 \pm 0.070^{\mathrm{b}}$ & $0.75 \pm 0.220^{\mathrm{b}, \mathrm{c}}$ & $1.22 \pm 0.149^{\mathrm{c}}$ & $<0.05$ \\
\hline GPx $(\mathrm{ng} / \mathrm{mL})$ & $0.64 \pm 0.067$ & $0.57 \pm 0.027^{\mathrm{b}}$ & $0.92 \pm 0.038^{\mathrm{b}}$ & $0.57 \pm 0.140$ & $<0.05$ \\
\hline SOD $(\mathrm{ng} / \mathrm{mL})$ & $0.20 \pm 0.038^{\mathrm{a}}$ & $0.30 \pm 0.062^{\mathrm{b}}$ & $0.84 \pm 0.234^{\mathrm{a}, \mathrm{b}, \mathrm{c}}$ & $0.22 \pm 0.049^{\mathrm{c}}$ & $<0.05$ \\
\hline Catalase $(\mathrm{ng} / \mathrm{mL})$ & $0.60 \pm 0.052$ & $0.51 \pm 0.025^{\mathrm{b}}$ & $0.68 \pm 0.035^{\mathrm{b}}$ & $0.55 \pm 0.049$ & $<0.05$ \\
\hline PND & 0 & $4.57 \pm 0.202^{\mathrm{b}}$ & $2.86 \pm 0.404^{\mathrm{b}, \mathrm{c}}$ & $4.00 \pm 0.309^{\mathrm{c}}$ & $<0.05$
\end{tabular}

MDA: Malondialdehyde, GPx: Glutathione peroxidase, SOD: Superoxide dismutase, PND: Prevalence of neuronal degeneration, SCl: Spinal cord injury, L: Lacosamide, PS: Physiological saline.

*One-way ANOVA test, ${ }^{a}$ Group 1 vs Group 3 (p<0.05), ${ }^{b}$ Group 2 vs Group $3(p<0.05),{ }^{c}$ Group 3 vs Group $4(p<0.05)$.

The serum GPx, SOD, catalase and MDA levels are also shown in Table I. There were statistically significant differences in the MDA levels between Groups 2 and 3 and Groups 3 and 4 $(p<0.05)$. The MDA level was lowest in Group 3. The catalase level in Group 3 was higher than in all other groups, but the difference was only statistically significant between Groups 2 and $3(p<0.05)$. The GPx level was also the highest in Group 3 with statistically significant differences in the levels between Groups 2 and 3 and Groups 2 and $4(p<0.05)$. The SOD levels were also highest in Group 3, and there was a statistically significant difference between these levels and those of all other groups $(p<0.05)$.

\section{DISCUSSION}

In the present study, we found that the MDA levels were the lowest and the antioxidant enzyme levels were the highest in Group 3, to whom lacosamide had been administered after $\mathrm{SCl}$. There was a statistically significant difference between Groups 2 and 3 for the following parameters: PND score, serum MDA, SOD, GPx and catalase levels after traumatic $\mathrm{SCl}$.

Initially, after $\mathrm{SCl}$, the vertebral fragments lead to contusion and compression of the cord, which is called the primary injury. Consecutively, the secondary injury phase starts, which is characterised by ischemic dysfunction, inflammation, oxidative stress and neuronal injury. This phase may last for weeks. The primary injury occurs at the time of trauma, and there is little that can be done to prevent its immediate effects. On the other hand, the long secondary injury phase has become target for interventions with experimental substances to prevent SCl. To this end, protection against free radicalmediated oxidative stress and lipid peroxidation are the main therapeutic strategies $(7,8,11,28)$. The neuroprotective effect of methylprednisolone, the only drug proven to be effective in large clinical studies, depends on its scavenger role for free oxygen radicals and its ability to inhibit lipid peroxidation.

To maintain normal cellular functions, a balance between oxidants and antioxidants is critical. In case of extreme oxidative stress, the oxidative damage outweighs the cellular antioxidant activity, which results in tissue injury (32). Reactive oxygen species (ROS) generated by oxidative stress are responsible for ongoing tissue injury. GPx, SOD and catalase are some of the antioxidant enzymes that protect against oxidative stress by inhibiting the production of ROS. SODs are a class of enzymes that catalyse the breakdown of the superoxide anion into oxygen and hydrogen peroxide. GPx reduces hydrogen peroxide and lipid peroxide to water and lipid alcohols. Catalases are also enzymes that catalyse the conversion of hydrogen peroxide to water and oxygen. If the activity of these enzymes is decreased, the amount of hydrogen peroxide increases, leading to direct tissue damage. After trauma, these enzymes are expected to increase as the body's defence system. This is why several studies in the literature examine the tissue and serum levels of these enzymes to assess the neuroprotective effect of drugs (17). Choi et al. reported increases of catalase and GPx expression after lacosamide pre-treatment that contributed to neuroprotection in experimentally induced transient cerebral ischaemia in gerbils (4). In our study, there was also an increase in GPx, SOD and catalase serum levels in the rats in Group 3 that had received lacosamide compared to all other groups, and the difference was statistically significant compared to the rats who did not receive lacosamide in Group 2. These results indicate a neuroprotective effect of lacosamide resulting from increased antioxidant enzyme activity.

Lipid peroxidation is another crucial step in the secondary injury phase after SCI $(16,20)$. It results in the damage of membrane lipids by ROS, which leads to cellular dysfunction because of altered membrane fluidity and permeability (32). MDA is the final product of these reactions, and in cases of increased ROS, such as in trauma, the amount of MDA increases as a result of tissue damage. Therefore, MDA is widely used as a marker of SCl. Solmaz et al. reported the potential lipid peroxidation-inhibiting effect of lacosamide on rats in a study on sepsis-induced critical illness polyneuropathy (27). Although sepsis and trauma are two different conditions, lipid peroxidation plays an important role in the etiopathogenesis of both. Therefore, we suggest that lacosamide, which reduces lipid peroxidation, also has a protective effect in SCI. Consequently, the decrease in MDA serum levels was an expected result in Group 3 and supports our hypothesis of a neuroprotective effect of lacosamide in $\mathrm{SCl}$. 
Previous studies reported that there is an association between ischaemic stroke and glial cell activation $(2,24)$. Furthermore, it was suggested that lacosamide was able to protect against ischemia-induced cell damage in neural tissue in the brain, and that this neuroprotective activity is associated with attenuation of glial cell activation (1). We also found that there was a lower PND score based on the microscopic examination of glial cell proliferation in Group 3 when compared with Groups 2 and 4 , and it was statistically significant $(p<0.05)$. Therefore, we suggest that lacosamide has a neuroprotective effect in $\mathrm{SCl}$ by inhibiting glial proliferation.

Our study has several limitations. We evaluated the antioxidant enzyme and MDA levels only in serum, not in the spinal cord tissue, as in many studies in the literature (3). Furthermore, there was no clinical evaluation of the rats after $\mathrm{SCl}$ and treatment. It might be a vital limitation of this study, but because we created only a mild damage to the spinal cord, most rats were ambulatory with only a mild deficiency, and there was no significant change in time to sacrification. Scoring was not significant since it showed similar clinical features. Therefore, we thought that the histological and biochemical evaluation might be sufficient. Finally, there was a relatively short followup period.

\section{CONCLUSION}

This study is the first to investigate the neuroprotective effects of lacosamide after SCI. The results of the biochemical and histological analyses revealed that lacosamide has a neuroprotective effect after experimental $\mathrm{SCl}$ in rats. This neuroprotective effect is related to its ability to decrease ROS production by increasing antioxidant enzyme expression, inhibit lipid peroxidation and attenuate glial cell activation.

\section{- REFERENCES}

1. Ahn JY, Yan BC, Park JH, Ahn JH, Lee DH, Kim IH, Cho JH, Chen BH, Lee JC, Cho YS, Shin MC, Cho JH, Hong S, Won $\mathrm{MH}$, Kim SK: Novel antiepileptic drug lacosamide exerts neuroprotective effects by decreasing glial activation in the hippocampus of a gerbil model of ischemic stroke. ExpTher Med 10:2007-2014, 2015

2. Bell MT, Puskas F, Agoston VA, Cleveland JC Jr, Freeman KA, Gamboni F, Herson PS, Meng X, Smith PD, Weyant MJ, Fullerton DA, Reece TB: Toll-like receptor 4 dependent microglial activation mediates spinal cord ischemiare perfusion injury. Circulation 128 Suppl 1:152-156, 2013

3. Celik H, Karatay M, Erdem Y, Yildirim AE, Sertbas I, Karatay E, Kul H, Guvenc Y, Koksal I, Menekse G, Alagoz F, Kertmen HH, Caydere M: The biochemical, histopathological and clinical comparison of the neuroprotective effects of subcutaneous adalimumab and intravenous methylprednisolone in an experimental compressive spinal cord trauma model. Turk Neurosurg 26:622-631, 2016
4. Choi HY, Park JH, Chen BH, Shin BN, Lee YL, Kim IH, Cho JH, Lee TK, Lee JC, Won MH, Ahn JH, Tae HJ, Yan BC, Hwang IK, Cho JH, Kim YM, Kim SK: Increases of catalase and glutathione peroxidase expressions by lacosamide pretreatment contributes to neuroprotection against experimentally induced transient cerebral ischemia. Neurochem Res 41:2380-2390, 2016

5. De Girolami U, Frosch MP, Tator $\mathrm{CH}$ : Regional neuropathology diseases of the spinal cord and vertebral column. In: Graham DI, Lantos PL, (eds). Greenfield's Neuropathology, $7^{\text {th }}$ ed. London: Arnold, 2002:1063-1101

6. Erol FS, Kaplan M, Tiftikci M, Yakar H, Ozercan I, Ilhan N, Topsakal C: Comparison of the effects of octreotide and melatonin in preventing nerve injury in rats with experimental spinal cord injury. J Clin Neurosci 15:784-790, 2008

7. Faden Al: Therapeutic approaches to spinal cord injury. Adv Neurol 72: 377-386, 1997

8. Faden Al, Salzman S: Pharmacological strategies in CNS trauma. Trends Pharmacol Sci 13:2935, 1992

9. Fedchenko N, Reifenrath J: Different approaches for interpretation and reporting of immunohistochemistry analysis results in the bone tissue - a review. Diagn Pathol 9:221, 2014

10. Gal P, Kravcukova P, Mokry M, Kluchova D: Chemokines as possible targets in modulation of the secondary damage after acute spinal cord injury: A review. Cell Mol Neurobiol 29:10251035, 2009

11. Hall ED, Braughler JM: Central nervous system trauma and stroke. II. Physiological and pharmacological evidence for involvement of oxygen radicals and lipid peroxidation. Free Radic Biol Med 6: 303-313, 1989

12. Hao JX, Stohr T, Selve N, Wiesenfeld-Hallin Z, Xu XJ: Lacosamide, a new antiepileptic, alleviates neuropathic painlike behaviors in rat models of spinal cord or trigeminal nerve injury. Eur J Pharmacol 553:135-140, 2006

13. Ildan F, Polat S, Oner A, Isbir T, Göcer Al, Tap O, Kaya M, Karadayi A: Effects of naloxone on sodiumand potassiumactivated and magnesium-dependent adenosine-5'triphosphatase activity and lipid peroxidation and early ultrastructural findings after experimental spinal cord injury. Neurosurgery 36:797-805, 1995

14. Kaptanoglu E, Solaroglu I, Okutan O, Surucu HS, Akbiyik F, Beskonakli E: Erythropoietin exerts neuroprotection after acute spinal cord injury in rats: Effect on lipid peroxidation and early ultrastructural findings. Neurosurg Rev 27:113-120, 2004

15. Kaptanoglu E, Tuncel M, Palaoglu S, Konan A, Demirpence E, Kilinc K: Comparison of the effects of melatonin and methylprednisolone in experimental spinal cord injury. J Neurosurg 93 Suppl 1:77-84, 2000

16. Koc RK, Akdemir H, Karakücük El, Oktem IS, Menkü A: Effect of methylprednisolone, tirilazadmesylate and vitamin $E$ on lipid peroxidation after experimental spinal cord injury. Spinal Cord 37:29-32, 1999

17. Kurtoglu T, Basoglu H, Ozkisacik EA, Cetin NK, Tataroglu C, Yenisey C, Discigil B: Effects of cilostazol on oxidative stress, systemic cytokine release, and spinal cord injury in a rat model of transient aortic occlusion. Ann Vasc Surg 28:479-488, 2014 
18. Marques SA, Garcez VF, Del Bel EA, Martinez AM: A simple, inexpensive and easily reproducible model of spinal cord injury in mice: Morphological and functional assessment. Journal of Neuroscience Methods 177:183-193, 2009

19. Menekse G, Daglioglu E, Nacar OA, Polat E, Ozdol C, Dalgic A, Take G, Okten Al, Belen AD: The neuroprotective effects of rituximab in rat spinal cord injury model: An immunohistochemical study. Turk Neurosurg 23:783-790, 2013

20. Oxidative stress. In: Halliwell B, Gutteridge JM (eds). Free Radicals in Biology and Medicine. $3^{\text {rd }}$ ed. New York: Oxford University Press, 1999:246-350

21. Pirouzmand F: Epidemiological trends of spine and spinal cord injuries in the largest Canadian adult trauma center from 1986 to 2006. J Neurosurg Spine 12:131-140, 2010

22. Pitkanen A, Immonen R, Ndode-Ekane X, Gröhn O, Stöhr T, Nissinen J: Effect of lacosamide on structural damage and functional recovery after traumatic brain injury in rats. Epilepsy Res 108:653-665, 2014

23. Rowland JW, Hawryluk GW, Kwon B, Fehlings MG: Current status of acute spinal cord injury pathophysiology and emerging therapies: Promise on the horizon. Neurosurg Focus 25:E2, 2008

24. Roy Choudhury G, Ryou MG, Poteet E, Wen Y, He R, Sun F, Yuan F, Jin K, Yang SH: Involvement of p38 MAPK in reactive astrogliosis induced by ischemic stroke. Brain Res 1551: 4558,2014

25. Sayer FT, Kronvall E, Nilsson OG: Methylprednisolone treatment in acute spinal cord injury: The myth challenged through a structured analysis of published literature. Spine J 6:335-343, 2006
26. Sengul G, Coban MK, Cakir M, Coskun S, Aksoy H, Hacimuftuoglu A, Saruhan F, Calik M: Neuroprotective effect of acute interferon-beta 1B treatment after spinal cord injury. Turk Neurosurg 23:45-49, 2013

27. Solmaz V, Aksoy D, Yılmaz M, Eser E, Erbas O: Demonstration of ameliorative effect of lacosamide: In a rat model of sepsis induced criticalillness polyneuropathy. Neurol Res 37:797802, 2015

28. Tator $\mathrm{CH}$, Fehlings MG: Review of the secondary injury theory of acute spinal cord trauma with emphasis on vascular mechanisms. J Neurosurg 75:15-26, 1991

29. Toklu HZ, Hakan T, Celik H, Biber N, Erzik C, Ogunc AV, Akakin D, Cikler E, Cetinel S, Ersahin M, Sener G: Neuroprotective effects of alpha-lipoic acid in experimental spinal cord injury in rats. J Spinal Cord Med 33:401-409, 2010

30. Tufan K, Oztanir N, Ofluoglu E, Ozogul C, Uzum N, Dursun A, Pasaoglu $\mathrm{H}$, Pasaoglu A: Ultrastructure protection and attenuation of lipid peroxidation after blockade of presynaptic release of glutamate by lamotrigine in experimental spinal cord injury. Neurosurg Focus 25:E6, 2008

31. Usul H, Arslan E, Cansever T, Cobanoglu U, Baykal S: Effects of clotrimazole on experimental spinal cord ischemia/ reperfusion injury in rats. Spine 33:2863-2867, 2008

32. Yang YH, Wang Z, Zheng J, Wang R: Protective effects of gallic acid against spinal cord injury-induced oxidative stress. Mol Med Rep 12:3017-3024, 2015

33. Young W: Medical treatments of acute spinal cord injury. J Neurol Neurosurg Psychiatry 55:635-639,1992 